\title{
Association of polymorphisms and haplotypes in the cytochrome P450 1B1 gene with uterine leiomyoma: A case control study
}

\author{
SAEEDEH SALIMI ${ }^{1,2}$, MARYAM KHODAMIAN ${ }^{2}$, MEHRNAZ NAROOIE-NEJAD $^{3,4}$, AZAM HAJIZADEH ${ }^{2}$, \\ KIMIA FAZELI $^{5}$, LIDA NAMAZI ${ }^{6}$ and MINOO YAGHMAEI ${ }^{6}$ \\ ${ }^{1}$ Cellular and Molecular Research Center, ${ }^{2}$ Department of Clinical Biochemistry, School of Medicine, \\ ${ }^{3}$ Department of Genetics, ${ }^{4}$ Genetics of Non-Communicable Disease Research Center, Zahedan University \\ of Medical Sciences, Zahedan; ${ }^{5}$ Faculty of Medicine, Mashhad University of Medical Sciences, \\ Mashhad 9137913316; ${ }^{6}$ Department of Obstetrics and Gynecology, School of Medicine, \\ Zahedan University of Medical Sciences, Zahedan 9816743175, Iran
}

Received November 20, 2014; Accepted December 18, 2014

DOI: $10.3892 /$ br.2014.413

\begin{abstract}
Uterine leiomyoma (UL) is an estrogen-dependent neoplasm of the uterus and estrogen metabolizing enzymes affect its promotion and progression. The aim of the present study was to evaluate the association between four single-nucleotide polymorphisms (SNPs) of the cytochrome P450 1B1 (CYPIB1) gene and UL risk. Four SNPs of the CYP1B1 gene in $105 \mathrm{UL}$ patients and 112 unrelated healthy controls were genotyped using a direct sequencing method. Haplotype analyses were performed with UNPHASED software and linkage disequilibrium (LD) was assessed by Haploview software. There were no associations between Leu432Val (rs1056836), Asp449Asp (rs1056837) and Asn453Ser (rs1800440) polymorphisms of the $C Y P 1 B 1$ gene and UL. Although the genotypic frequencies of the Arg368His (rs79204362) polymorphism did not differ between the two groups, the frequency of A (His) allele was significantly higher in UL females $(\mathrm{P}=0.02)$. In addition, the frequency of GTAA haplotype was significantly higher in the controls and played a protective role in UL susceptibility. A strong LD between the three common SNPs (rs1056836, rs1056837 and rs1800440) in the $C Y P 1 B 1$ gene was observed in the population. In conclusion, a higher frequency of the CYP1B1 368His (A) allele was observed in UL females. The frequency of the GTAA haplotype was significantly higher in healthy females and this haplotype played a protective role in UL susceptibility.
\end{abstract}

Correspondence to: Miss. Maryam Khodamian, Department of Clinical Biochemistry, School of Medicine, Zahedan University of Medical Sciences, Khalij-e Fars High Way , Zahedan 9816743175 , Iran

E-mail: maryam.khodamian@yahoo.com

Key words: uterine leiomyoma, CYP1B1, gene, polymorphism, haplotype

\section{Introduction}

Uterine leiomyoma (UL) is a benign monoclonal tumor of the smooth muscle cells, which arises more specifically from the underlying myometrial tissue in the uterus (1). These tumors contain high amounts of extracellular matrix components, such as collagen, fibronectin and proteoglycans (2). UL has been diagnosed in $30-40 \%$ of females at a reproductive age and is the leading indication for hysterectomy (1). Although this complication is often asymptomatic, it may result in symptoms including abdominal discomfort to uterine bleeding, menometrorrhagia, severe dysmenorrhea, pelvic pain and infertility (3). Despite the high prevalence of UL, the associated pathophysiology and proliferative pathway remains unknown. Different risk factors have been suggested for UL, including age, endogenous hormone levels (estrogen and progesterone), certain enzymes, obesity, nulliparity and genetic factors $(2,3)$. The genetic liability of UL is supported by the fact that hysterectomy and hospitalization due to UL is twice as high in monozygote female twins compared to dizygotes $(4,5)$.

$\mathrm{UL}$ is an estrogen-dependent tumor and is more prevalent during the reproductive age. The estrogen hormone stimulates the progression of cell proliferation in the $G_{1}$ phase of the cell cycle in various target tissues, including the uterus and breast $(2,6)$. Evidence has shown that leiomyoma tissue is more sensitive to estrogen compared to myometrium and the concentration of estrogen in leiomyoma tissue is higher compared to the normal myometrium. Additionally, the leiomyoma growth is regulated by serum estrogen and estrogen in the tumor (7).

Estrogen exerts its biological effect through the high affinity binding to estrogen receptors (ESR $\alpha$ and $\operatorname{ESR} \beta)$ and muscle cells with leiomyoma express $\alpha$ and $\beta$ ESRs $(8,9)$.

The P450 cytochrome system (CYP450) contains a group of enzymes that are involved in steroid hormone biosynthesis and metabolic activation of carcinogens $(10,11)$. Five different enzymes have been identified in this system, which are involved in estrogen synthesis and degradation. Cytochrome 
79204362

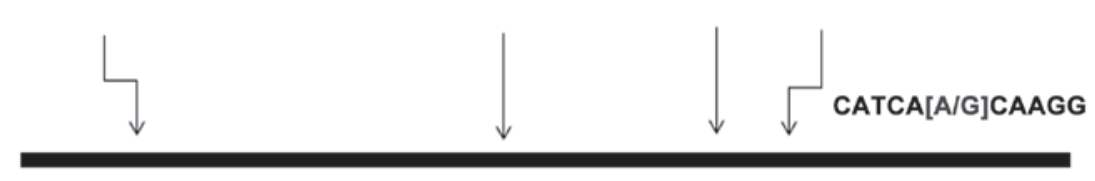

GGACC[A/G]TCTGC
ACCCA[C/G]TGAAG
AAGGA[A/C/T]GGCCT

Figure 1. Schematic diagram of the distribution of four single-nucleotide polymorphism (SNP) loci in the cytochrome P450 1B1 (CYP1B1) gene.

P450 17a (CYP17) and cytochrome P450 19 (CYP19 or aromatase) control the early and terminal steps of the estrogen biosynthesis pathway respectively (12).

Cytochrome P450 1A1 (CYP1A1) and cytochrome P450 1B1 (CYP1B1) are the main enzymes of the CYP450 system in estrogen catabolism that catalyze the formation of 2-hydroxy and 4-hydroxy estrogen metabolites. Catechol-O-methyl transferase catalyzes the excretion of carcinogenic 4-hydroxy estrogen metabolites (12). Certain evidence has shown that human endometrial epithelium produce cytochrome P450 (CYP P450) metabolic enzymes that generate genotoxic intermediates and affect ESRs. Therefore, these enzymes are associated with carcinogenesis in extrahepatic tissues $(13,14)$. The study by Shastry $(15)$ found high 4-hydroxylase activities in human uterine myometrium and benign UL. This evidence strongly proposes that estrogens and their metabolic products affect the occurrence and development of UL. Therefore, $C Y P 1 A 1$ and $C Y P 1 B 1$ variants are expected to affect estrogen synthesis or degradation (16).

The association between polymorphisms of estrogen-metabolizing enzyme genes and UL susceptibility have been studied in different populations, however, their results were inconsistent $(14,17)$. Therefore, in the present study the association between Arg368His (rs79204362), Leu432Val (rs1056836), Asp449Asp (rs1056837) and Asn453Ser (rs1800440) polymorphisms of the $C Y P 1 B 1$ gene and UL susceptibility was examined in southeast Iran.

\section{Materials and methods}

Subject characteristics. The present case control study was performed on 105 females in their pre-menopausal stage that had undergone myomectomy or hysterectomy in Ali Ibn Abitaleb Hospital, Zahedan, southeast Iran, and were enrolled between 2011 and 2013. All the participants were selected using the convenient sampling method. In all the participants, leiomyoma had been confirmed pathologically.

In total, 112 healthy females in their premenopausal stage were selected as the control group among females referring for a routine annual check-up and performing the Pap smear test. The groups were matched with respect to demographic factors, such as age and ethnicity (Fars or Balouch). Physical and ultrasonographic evaluations were performed for females in the control group to elimate UL. The Pap smear test was also negative.

The exclusion criteria were existence of systemic diseases and history of malignancy. All the participants were Iranian and provided their informed consent prior to participating in the study. The protocol of the study was approved by the Ethics Committee of Zahedan University of Medical Sciences.

Genotype analysis. Genomic DNA was extracted from $2 \mathrm{ml}$ peripheral blood leukocytes using the salting out phenol chloroform method and stored at $-20^{\circ} \mathrm{C}$ until analysis. The analysis of the $C Y P 1 B 1$ polymorphisms was performed using the sequencing method.

The reference sequence was the human $C Y P 1 B 1$ gene (GeneBankaccession numberU56438).Thefragmentcontaining all the polymorphisms was amplified using the forward and reverse primers of 5'-TCACTTGCTTTTCTCTCTCC-3' and 5'-AATTTCAGCTTGCCTCTTG-3', respectively (18).

The total volume of the PCR mixture was $25 \mu 1$ and contained $300 \mathrm{ng}$ genomic DNA, $25 \mathrm{pM}$ of each primers, $0.1 \mathrm{mM}$ dNTP, $1.5 \mathrm{mM} \mathrm{MgCl}_{2}, 2.5 \mu \mathrm{l}$ PCR buffer $10 \mathrm{X}$ and 1 unit of Taq polymerase.

Amplification was performed in a Bio-Rad thermal cycler (Bio-Rad, Hercules, CA, USA) using a thermal profile of initial denaturation at $96^{\circ} \mathrm{C}$ for $6 \mathrm{~min}$, followed by 30 cycles at $96^{\circ} \mathrm{C}$ for $30 \mathrm{sec}$, annealing at $61^{\circ} \mathrm{C}$ for 40 -base pair insertion/deletion polymorphism and $60^{\circ} \mathrm{C}$ for $\mathrm{T} 309 \mathrm{G}$ polymorphism for $30 \mathrm{sec}$, primer extension at $72^{\circ} \mathrm{C}$ for $60 \mathrm{sec}$, and a final extension step at $72^{\circ} \mathrm{C}$ for $6 \mathrm{~min}$.

The PCR products were sequenced in a forward direction with the same primers as used in the PCR, using ABI Big Dye terminator chemistry and an ABI PRISM 3730/3730xl instrument (Applied Biosystems, Foster City, CA, USA).

A schematic diagram of Arg368His (rs79204362), Leu432Val (rs1056836), Asp449Asp (rs1056837) and Asn453Ser (rs1800440) polymorphisms of the CYP1Bl gene is presented in Fig. 1.

Statistical analysis. Statistical analyses were performed using SPSS software, version 20 (IBM Corp, Armonk, NY, USA). The frequency of the genotypes and alleles were compared between two groups using the $\chi^{2}$ or Fisher's exact tests. Quantitative variables were compared using the Student's t-test. Odds ratios (OR) and 95\% confidence intervals (CI) were accounted to the significant allelic and genotypic associations. $\mathrm{P}<0.05$ was considered to indicate a statistically significant difference.

The frequency of haplotypes was calculated using PHASE version 2.1 software $(19,20)$. Haplotypes with estimated frequency $<5 \%$ were excluded from the analysis. Logistic regression analysis was used to assess the independent effect of each risk polymorphism and haplotypes on UL. Bonferroni's correction was applied to confirm the association of haplotypes with the disease. 
The computation of linkage disequilibrium (LD) between single-nucleotide polymorphisms (SNPs) was estimated using the normalized measure of allelic association $D^{\prime}$ and the characterization of these patterns was determined using Haploview 4.2 software (http://www.borad.mit.edu/mpg/ haploview).

\section{Results}

Subject characteristics. The demographic and clinical characteristics of the UL patients and controls are shown in Table I. No significant differences in the age, body mass index and marital status between the two groups were observed. There were no significant differences in menstrual histories, including duration of menstruations, age of menarche and menstrual cycle between the two groups. Additionally, the frequency of bleeding and pain were significantly higher in the UL females $(\mathrm{P}<0.0001)$.

Genotyping of CYP1B1 SNPs. Four SNPs of the CYP1B1 gene were successfully genotyped in $105 \mathrm{UL}$ females and 112 healthy controls. The frequency of alleles and genotypes of $C Y P 1 B 1$ polymorphisms are shown in Table II. All the loci conformed to the Hardy-Weinberg equilibrium in UL females and control groups $(\mathrm{P}>0.05)$. The frequency of the $C Y P 1 B 1$ $432 \mathrm{Val}(\mathrm{G})$ allele in females with UL and controls were 38 and $30 \%$, respectively, and the difference was not statistically significant. The genotype frequency of the CYP1B1 Leu432Val polymorphism was not significantly different between the two groups. Although the frequency of the CYP1B1 449Asp (T) allele was higher in the UL group compared to controls (38 vs. 31\%), the difference was not significant. The genotype frequency of the CYP1B1 Asp449Asp (T/C) polymorphism was not significantly different between the two groups.

Genotype frequencies of polymorphisms. Although there was no significant difference in the genotypes frequency of the Arg368His (G/A) polymorphism between UL females and controls, a higher frequency of the A allele was observed in UL females compared to healthy females (13 vs. 6\%) and the risk of UL was increased to 2.2-fold in the presence of the A allele (OR, 2.2; 95\% CI, 1.1-4.4; $\mathrm{P}=0.02)$. There was no association between $C Y P 1 B 1$, Asn453Ser (A/G) polymorphism and UL. The CYP1B1 Arg368His (rs79204362) polymorphism has not been found in HapMap. Therefore, the LD patterns of the three $C Y P 1 B 1$ SNPs were analyzed, as shown in Fig. 2. There was a strong LD between the three common SNPs in $C Y P 1 B 1$ gene.

The frequency of five common haplotypes of four SNPs in the CYP1B1 gene [Leu432Val (C/G), Asp449Asp (T/C), Asn453Ser (A/G) and Arg368His (G/A)] are shown in Table III.

Although the frequency of the CCGG haplotype was higher in UL females compared to the controls (24 vs. 18\%), the difference was not statistically significant $(\mathrm{P}=0.3)$. The frequency of the GTAA haplotype in controls was significantly higher than that of the cases $(12.7$ vs. $6 \%, \mathrm{P}=0.039)$ and the haplotype-based association analysis revealed that the GTAA haplotype may have potential to protect against UL in females (OR, 0.8; 95\% CI, 0.7-1; $\mathrm{P}=0.039$ ). This association was also statistically significant following Bonferroni's correction.
Table I. Demographic and clinical characteristics of the UL females and control group.

\begin{tabular}{lccc}
\hline & $\begin{array}{c}\text { UL females } \\
(\mathrm{n}=105)\end{array}$ & $\begin{array}{c}\text { Controls } \\
(\mathrm{n}=112)\end{array}$ & P-value \\
\hline Age, years & $38.1 \pm 9.8$ & $36.7 \pm 5.7$ & 0.23 \\
Marriage status, n (\%) & $100(95)$ & $109(97)$ & 0.49 \\
BMI, kg/m ${ }^{2}$ & $25.1 \pm 5.5$ & $25.4 \pm 4.7$ & 0.70 \\
Age of menarche, years & $13.5 \pm 1.5$ & $13.1 \pm 1.6$ & 0.07 \\
Duration of menses, days & $6.1 \pm 1.6$ & $5.8 \pm 1.5$ & 0.07 \\
Menstrual cycle, days & $28.3 \pm 3.3$ & $28.7 \pm 2.1$ & 0.30 \\
Bleeding, n (\%) & $60(57)$ & $4(4)$ & $<0.0001$ \\
Pain, n $(\%)$ & $30(29)$ & $6(5)$ & $<0.0001$ \\
\hline
\end{tabular}

Data are mean \pm standard deviation. UL, uterine leiomyoma; BMI, body mass index.

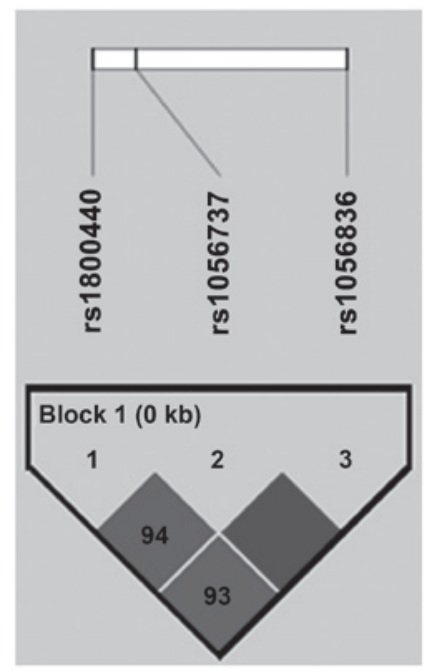

Figure 2. Linkage disequilibrium pattern of three single-nucleotide polymorphisms (SNPs) in the cytochrome P450 1B1 (CYP1B1) gene.

\section{Discussion}

In the present study, there was no association between the Leu432Val, Asp449Asp and Asn453Ser polymorphisms of the $C Y P 1 B 1$ gene and SLE. However, a higher frequency of the A allele of Arg368His (G/A) polymorphism was observed in UL females compared to healthy females and according to the current findings, the presence of the A allele increased the SLE risk. In addition, the frequency of the GTAA haplotype in the controls was significantly higher compared to the patients; therefore, the GTAA haplotype played a protective role in SLE susceptibility. A strong LD between the three common SNPs in the $C Y P 1 B 1$ gene was observed in the population of the present study.

UL is a common neoplasm associated with an interaction between various genes, cytokines, growth factors, hormones and environmental factors. Whether ovarian steroid hormones play an essential role in the growth of leiomyoma is unknown. The mitogenic effects of steroid hormones are induced through their receptors or by regulation of growth factor expression $(7,8)$. 
Table II. Allelic and genotypic frequency of the CYP1B1 gene polymorphisms in UL females and healthy controls.

\begin{tabular}{|c|c|c|c|c|c|c|}
\hline$C Y P 1 B 1$ & $\begin{array}{l}\text { UL females } \\
\qquad(\mathrm{n}=105)\end{array}$ & $\begin{array}{l}\text { Controls } \\
(\mathrm{n}=112)\end{array}$ & P-value & $\begin{array}{l}\text { Non-adjusted } \\
\text { OR }(95 \% \text { CI })\end{array}$ & P-value & $\begin{array}{l}\text { Adjusted OR } \\
(95 \% \mathrm{CI})^{\mathrm{a}}\end{array}$ \\
\hline \multicolumn{7}{|c|}{ Leu432Val (C/G) rs1056836 } \\
\hline $\mathrm{CC}, \mathrm{n}(\%)$ & $42(40)$ & $56(50)$ & & 1 & & 1 \\
\hline $\mathrm{CG}, \mathrm{n}(\%)$ & $47(45)$ & $45(40)$ & 0.30 & $1.4(0.8-2.5)$ & 0.30 & $1.4(0.8-2.4)$ \\
\hline $\mathrm{GG}, \mathrm{n}(\%)$ & $16(15)$ & $11(10)$ & 0.13 & $1.3(0.8-2.0)$ & 0.20 & $1.4(0.9-2.1)$ \\
\hline $\mathrm{CG}+\mathrm{GG}, \mathrm{n}(\%)$ & $63(60)$ & $56(50)$ & 0.14 & $1.5(0.9-2.6)$ & 0.20 & $1.5(0.8-2.5)$ \\
\hline $\mathrm{C}, \mathrm{n}(\%)$ & $131(62)$ & $157(70)$ & & 1 & & - \\
\hline $\mathrm{G}, \mathrm{n}(\%)$ & $79(38)$ & $67(30)$ & 0.09 & $1.4(1.0-2.1)$ & & - \\
\hline \multicolumn{7}{|c|}{ Asp449Asp (T/C) rs1056837 } \\
\hline $\mathrm{CC}, \mathrm{n}(\%)$ & $42(40)$ & $53(47)$ & & 1 & & 1 \\
\hline $\mathrm{CT}, \mathrm{n}(\%)$ & $47(45)$ & $48(43)$ & 0.50 & $1.2(0.7-2.2)$ & 0.50 & $1.2(0.7-2.2)$ \\
\hline $\mathrm{TT}, \mathrm{n}(\%)$ & $16(15)$ & $11(10)$ & 0.20 & $1.4(0.9-2.1)$ & 0.30 & $1.3(0.8-2.0)$ \\
\hline $\mathrm{CT}+\mathrm{TT}, \mathrm{n}(\%)$ & $63(60)$ & $59(53)$ & 0.30 & $1.4(0.8-2.3)$ & 0.30 & $1.3(0.8-2.3)$ \\
\hline $\mathrm{C}, \mathrm{n}(\%)$ & $131(62)$ & $154(69)$ & & 1 & & \\
\hline $\mathrm{T}, \mathrm{n}(\%)$ & $79(38)$ & $70(31)$ & 0.19 & $1.3(0.9-2.0)$ & & \\
\hline \multicolumn{7}{|c|}{ Asn453Ser (A/G) rs 1800440} \\
\hline AA & $71(68)$ & $64(57)$ & & 1 & & \\
\hline $\mathrm{AG}$ & $29(27)$ & $42(37)$ & 0.11 & $0.6(0.4-1.1)$ & 0.12 & $0.6(0.4-1.1)$ \\
\hline GG & $5(5)$ & $6(6)$ & 0.70 & $0.9(0.5-1.6)$ & 0.70 & $0.9(0.5-1.6)$ \\
\hline $\mathrm{AG}+\mathrm{GG}$ & $34(32)$ & $48(43)$ & 0.11 & $0.6(0.4-1.1)$ & 0.12 & $0.7(0.4-1.1)$ \\
\hline \multicolumn{7}{|l|}{ Allele } \\
\hline A & $171(82)$ & $170(76)$ & & & & \\
\hline G & $39(18)$ & $54(24)$ & 0.16 & $0.7(0.5-1.1)$ & & \\
\hline \multicolumn{7}{|c|}{ Arg368His (G/A) rs79204362 } \\
\hline GG & $81(77)$ & $98(88)$ & & 1 & & \\
\hline GA & $21(20)$ & $14(13)$ & 0.11 & $1.8(0.9-3.8)$ & 0.11 & $1.8(0.9-3.8)$ \\
\hline AA & $3(3)$ & $0(0)$ & - & - & - & - \\
\hline $\mathrm{GA}+\mathrm{AA}$ & $24(23)$ & $14(13)$ & 0.11 & $1.8(0.9-3.8)$ & 0.11 & $1.8(0.9-3.8)$ \\
\hline \multicolumn{7}{|l|}{ Allele } \\
\hline $\mathrm{G}$ & $183(87)$ & $210(94)$ & & & & \\
\hline A & $27(13)$ & $14(6)$ & 0.02 & $2.2(1.1-4.4)$ & & \\
\hline
\end{tabular}

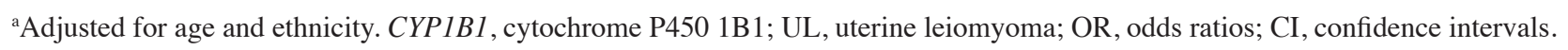

Table III. Haplotypes frequency of the CYP1B1 gene polymorphisms in UL patients and controls.

\begin{tabular}{|c|c|c|c|c|c|c|c|}
\hline \multicolumn{4}{|c|}{ CYPIBI SNPs } & \multirow{2}{*}{$\begin{array}{l}\text { Leiomyoma } \\
\quad(\mathrm{n}=105)\end{array}$} & \multirow{2}{*}{$\begin{array}{l}\text { Control } \\
(\mathrm{n}=112)\end{array}$} & \multirow[b]{2}{*}{ P-value } & \multirow[b]{2}{*}{ OR $(95 \% \mathrm{CI})$} \\
\hline rs1056836 & rs 1056837 & rs 1800440 & rs79204362 & & & & \\
\hline $\mathrm{C}$ & $\mathrm{C}$ & A & G & 0.446518 & 0.445568 & & 1 \\
\hline $\mathrm{C}$ & $\mathrm{C}$ & G & $\mathrm{G}$ & 0.240873 & 0.177685 & 0.30 & $1.3(0.8-2.2)$ \\
\hline $\mathrm{C}$ & $\mathrm{T}$ & A & $\mathrm{G}$ & 0.013393 & 0 & 0.10 & - \\
\hline G & $\mathrm{T}$ & A & $\mathrm{G}$ & 0.236670 & 0.240574 & 0.95 & $1.0(0.9-1.2)$ \\
\hline G & $\mathrm{T}$ & A & A & 0.062302 & 0.127683 & $0.039^{\mathrm{a}}$ & $0.8(0.7-1)$ \\
\hline
\end{tabular}

${ }^{\text {aP }}<0.05$. CYP1B1, cytochrome P450 1B1; SNP, single-nucleotide polymorphism; UL, uterine leiomyoma; OR, odds ratios; CI, confidence intervals. 
The UL development possibly occurs in response to a certain type of injury to the myometrium, such as hypoxia (21).

CYP1B1 is known as a key enzyme that metabolizes a variety of putative human carcinogens and estrogens. Certain evidence stated that this enzyme may play an essential role in tumor development and progression (22). Therefore, polymorphisms in the CYPIBI gene may affect the metabolism of environmental estrogens and hormone-like substances. The polymorphisms influenced the inter-individual risk of developing a tumor (22). The CYP1B1 enzyme catalyzes the conversion of estrogens to 4-hydroxy estrogen metabolites and recent products can increase the quantity of estrogen within the cells by activating the ESR. Certain evidence has shown that the CYP1B1 variants are more efficient in the conversion and accumulation of carcinogenic estrogens $(23,24)$.

Thus, inherited variations in the CYP1B1 activity lead to differences in estrogen metabolism and explain inter-individual differences in the UL risk in association with estrogen-mediated tumorogenesis (25).

Several studies have addressed the association between the genetic polymorphisms of enzymes involved in the estrogen metabolism and the occurrence of UL (14,17,26,27). In 2006, Herr et al (26) reported a significant correlation between CYP2A13 and CYP1A1 SNPs and UL in a Caucasian population. The genetic distribution of Ile462Val and T6235C polymorphisms of the CYP1A1 gene and Arg48Gly, Ala119Ser, Leu432Val and Asp449Asp polymorphisms of the CYP1B1 gene were studied by Ye et al (17) in Chinese females. The studies reported that only the CYPIAl Ile462Val polymorphism was associated with the increased risk of UL. However, similar to the findings of the present study, there was no association between polymorphisms of the $C Y P 1 B 1$ gene and UL susceptibility in China. Despite the results of Ye et al (17) in Chinese females, El-Shennawy et al (14) observed an elevated risk of UL in females with the CC genotype of the CYP1BI Leu432Val $(\mathrm{C} / \mathrm{G})$ polymorphism and according to their results this genotype can predict the susceptibility to UL in Egyptian females. Shen et al $(27,28)$ studied the association between the Ala119Ser, Leu432Val and Asp449Asp polymorphisms of the $C Y P 1 B 1$ gene and UL in Han Chinese females. Consistent with the results of the present study, an association between the Asp449Asp (T/C) polymorphism gene and UL was not observed, however, the studies found that the Ala119Ser polymorphism was a risk factor and the Leu432Val polymorphism was a protective factor for UL development. The present study findings showed a strong LD between the three common SNPs in the CYP1B1 gene in the population. Similarly, Bethke et al (29) observed a strong LD between the five common SNPs in the CYP1Bl gene in UK.

To the best of our knowledge, this is the first study regarding the effect of $C Y P 1 B 1$ haplotypes (four SNPs) on UL susceptibility, therefore, further studies in different populations are required to evaluate the association between $C Y P 1 B 1$ haplotypes and UL.

In conclusion, there was an association between the A (His) allele of the CYP1B1 Arg368His (rs79204362) polymorphism and UL. In addition, the GTAA haplotype may play a protective role in SLE susceptibility. There was a strong LD between the three common SNPs (rs1056836, rs1056837 and rs1800440) of the $C Y P 1 B 1$ gene in the southeast Iranian population.

\section{Acknowledgements}

The present study was extracted from an MS thesis (registered no. 2162; Comparison of CYP1A1 and Cyp1B1 genes polymorphism in women with leiomyoma and controls, by Dr Saeedeh Salimi, Maryam Khodamian and Dr Minoo Yaghmaei, 2013) at Zahedan University of Medical Sciences. The authors would like to thank the Deputy of Research Affairs at the University for funding the study.

\section{References}

1. Falcone T and Walters MD: Hysterectomy for benign disease. Obstet Gynecol 111: 753-767, 2008.

2. Parker WH: Etiology, symptomatology, and diagnosis of uterine myomas. Fertil Steril 87: 725-736, 2007.

3. Sell SM, Tullis C, Stracner D, Song CY and Gewin J: Minimal interval defined on $7 \mathrm{q}$ in uterine leiomyoma. Cancer Genet Cytogenet 157: 67-69, 2005.

4. Luoto R, Kaprio J, Rutanen EM, Taipale P, Perola M and Koskenvuo M: Heritability and risk factors of uterine fibroids the Finnish Twin Cohort study. Maturitas 37: 15-26, 2000.

5. Treloar SA, Martin NG, Dennerstein L, Raphael B and Heath AC: Pathways to hysterectomy: insights from longitudinal twin research. Am J Obstet Gynecol 167: 82-88, 1992.

6. Sabbah M, Courilleau D, Mester J and Redeuilh G: Estrogen induction of the cyclin D1 promoter: involvement of a cAMP response-like element. Proc Natl Acad Sci USA 96: 11217-11222, 1999.

7. Urabe M, Yamamoto T, Naito K, Kitawaki J, Honjo $\mathrm{H}$ and Okada H: Study on the local estrogen biosynthesis in human uterine leiomyoma. Nihon Sanka Fujinka Gakkai Zasshi 42: 1229-1236, 1990 (In Japanese).

8. Roodi N, Bailey LR, Kao WY, et al: Estrogen receptor gene analysis in estrogen receptor-positive and receptor-negative primary breast cancer. J Natl Cancer Inst 87: 446-451, 1995.

9. Jakimiuk AJ, Bogusiewicz M, Tarkowski R, et al: Estrogen receptor alpha and beta expression in uterine leiomyomas from premenopausal women. Fertil Steril 82 (Suppl 3): 1244-1249, 2004.

10. Stiborová M, Martínek V, Rýdlová H, Koblas T and Hodek P: Expression of cytochrome P450 1A1 and its contribution to oxidation of a potential human carcinogen 1-phenylazo-2-naphthol (Sudan I) in human livers. Cancer Lett 220: 145-154, 2005.

11. Somner J, McLellan S, Cheung J, et al: Polymorphisms in the P450 c17 (17-hydroxylase/17,20-Lyase) and P450 c19 (aromatase) genes: association with serum sex steroid concentrations and bone mineral density in postmenopausal women. J Clin Endocrinol Metab 89: 344-351, 2004.

12. Ashton KA, Proietto A, Otton G, et al: Polymorphisms in genes of the steroid hormone biosynthesis and metabolism pathways and endometrial cancer risk. Cancer Epidemiol 34: 328-337, 2010.

13. Hukkanen J, Mäntylä M, Kangas L, et al: Expression of cytochrome $\mathrm{P} 450$ genes encoding enzymes active in the metabolism of tamoxifen in human uterine endometrium. Pharmacol Toxicol 82: 93-97, 1998.

14. El-Shennawy GA, Elbialy AA, Isamil AE and El Behery MM: Is genetic polymorphism of ER- $\alpha$, CYP1A1, and CYP1B1 a risk factor for uterine leiomyoma? Arch Gynecol Obstet 283: 1313-1318, 2011.

15. Shastry BS: SNP alleles in human disease and evolution. J Hum Genet 47: 561-566, 2002.

16. Maruo T, Ohara N, Wang J and Matsuo H: Sex steroidal regulation of uterine leiomyoma growth and apoptosis. Hum Reprod Update 10: 207-220, 2004.

17. Ye Y, Cheng X, Luo HB, Liu L, Li YB and Hou YP: CYP1A1 and CYP1B1 genetic polymorphisms and uterine leiomyoma risk in Chinese women. J Assist Reprod Genet 25: 389-394, 2008.

18. Zheng W, Xie DW, Jin F, et al: Genetic polymorphism of cytochrome P450-1B1 and risk of breast cancer. Cancer Epidemiol Biomarkers Prev 9: 147-150, 2000

19. Stephens M and Donnelly P: A comparison of bayesian methods for haplotype reconstruction from population genotype data. Am J Hum Genet 73: 1162-1169, 2003. 
20. Scheet P and Stephens M: A fast and flexible statistical model for large-scale population genotype data: applications to inferring missing genotypes and haplotypic phase. Am J Hum Genet 78 : 629-644, 2006

21. Mesquita FS, Dyer SN, Heinrich DA, Bulun SE, Marsh EE and Nowak RA: Reactive oxygen species mediate mitogenic growth factor signaling pathways in human leiomyoma smooth muscle cells. Biol Reprod 82: 341-351, 2010.

22. Aklillu E, Oscarson M, Hidestrand M, Leidvik B, Otter C and Ingelman-Sundberg M: Functional analysis of six different polymorphic CYP1B1 enzyme variants found in an Ethiopian population. Mol Pharmacol 61: 586-594, 2002.

23. Hayes CL, Spink DC, Spink BC, Cao JQ, Walker NJ and Sutter TR: 17 beta-estradiol hydroxylation catalyzed by human cytochrome P450 1B1. Proc Natl Acad Sci USA 93: 9776-9781, 1996.

24. Zhu BT and Conney AH: Functional role of estrogen metabolism in target cells: review and perspectives. Carcinogenesis 19: 1-27, 1998.

25. Houston KD, Hunter DS, Hodges LC and Walker CL: Uterine leiomyomas: mechanisms of tumorigenesis. Toxicol Pathol 29: 100-104, 2001.
26. Herr D, Bettendorf H, Denschlag D, Keck C and Pietrowski D: Cytochrome P2A13 and P1A1 gene polymorphisms are associated with the occurrence of uterine leiomyoma. Arch Gynecol Obstet 274: 367-371, 2006.

27. Shen Y, Ren ML, Xu J, et al: A multicenter case-control study on screening of single nucleotide polymorphisms in estrogen-metabolizing enzymes and susceptibility to uterine leiomyoma in han chinese. Gynecol Obstet Invest 77: 224-230, 2014.

28. Shen Y, Xu Q, Ren M, Cai Y and Xu J: Role of single nucleotide polymorphisms in estrogen-metabolizing enzymes and susceptibility to uterine leiomyoma in Han Chinese: a case-control study. J Obstet Gynaecol Res 40: 1077-1084, 2014

29. Bethke L, Webb E, Sellick G, et al: Polymorphisms in the cytochrome P450 genes CYP1A2, CYP1B1, CYP3A4, CYP3A5, CYP11A1, CYP17A1, CYP19A1 and colorectal cancer risk. BMC Cancer 7: 123, 2007. 